\title{
Problem-Based Learning of Drug Use and Abuse during COVID-19 Contingency
}

\author{
Abraham Isaías López-González¹, Oscar Diego Vega-Rodríguez¹, \\ Verónica Paolette Cañas-Pacheco ${ }^{1}$, Rafael Villalobos-Molina ${ }^{2}$ (i), \\ Diana Cecilia Tapia-Pancardo ${ }^{*}$ (1)
}

\author{
${ }^{1}$ Nursing Career, Faculty of Higher Studies Iztacala, National Autonomous University of Mexico, Tlalnepantla, Mexico \\ ${ }^{2}$ Graduate and Research Division, Biomedicine Unit, Faculty of Higher Studies Iztacala, National Autonomous University of \\ Mexico, Tlalnepantla, Mexico \\ Email: *dianacecitapia@hotmail.com
}

How to cite this paper: López-González, A.I., Vega-Rodríguez, O.D., Cañas-Pacheco, V.P., Villalobos-Molina, R. and Tapia-Pancardo, D.C. (2022) Problem-Based Learning of Drug Use and Abuse during COVID-19 Contingency. Open Journal of Nursing, 12, 170-180. https://doi.org/10.4236/ojn.2022.122011

Received: February 1, 2022

Accepted: February 22, 2022

Published: February 25, 2022

Copyright $\odot 2022$ by author(s) and Scientific Research Publishing Inc. This work is licensed under the Creative Commons Attribution International License (CC BY 4.0).

http://creativecommons.org/licenses/by/4.0/

\begin{abstract}
Introduction: Nursing students' experiences during the pandemic provoked social isolation, the way to learn and every context increasing their stress and anxiety leading to drug use and abuse, among others. Problem-based learning (PBL) is a pedagogic strategy to strengthen significant learning; then the objective was to establish PBL influence in nursing students' experiences on drug use and abuse during COVID-19 contingency. Methods: Qualitative, phenomenological and descriptive paradigm, 12 female and male nursing students aged 20 - 24 years old from the $5^{\text {th }}$ and $6^{\text {th }}$ semesters participated. Information collection was through semi-structured interview and a deep one in four cases. A guide of questions about: How the pandemic impacted your life? How did you face it? And what did you learn during this process? Those questions were used. Qualitative data analysis was based on De Souza Minayo, and signed informed consent was obtained from participants. Results: Students' experiences allowed four categories to emerge, with six sub-categories. Category I. Students' experiences on drug use and abuse facing the sanitary contingency; Category II. Students' skills development to identify a problem and design of appropriate solutions; Category III. Developing skills to favor interpersonal relationships; Category IV. Influence of PBL in nursing students' experiences on drug use and abuse during the COVID-19 contingency. Conclusion: PBL favored analysis and thoughts in nursing students' experiences on drug use and abuse during the COVID-19 contingency, they worked collaboratively, developed resilience to daily life situations, and implemented stress coping strategies with their significant learning, which diminished their risk behavior.
\end{abstract}

\section{Keywords}

Problem-Based Learning, Students' Experiences in Drug Use and Abuse, 


\section{Introduction}

In the context of COVID-19 pandemic, it is necessary to comprehend the possible changes in the patterns of alcohol, psychopharmaceuticals, major painkillers, and the experiential or sporadic use of other depressant drugs, either stimulant or disturbing the central nervous system, to alleviate displeasure, anxiety and fears. It is known that youngsters are vulnerable to consumption, increased in the pandemic due to social isolation, modifying study habits, family and social coexistence leading to anxiety. Social distancing broke the preventive and therapeutic models to face the problematic drugs consumption, related to in-person group strategies in patients and their socio-affective relatives; as well as inclusion and integration process of drug users in the community scenarios of the drug-attention care network. Tobacco, alcohol and drugs consumption is a public health problem long before the pandemic, current data show that drugs use increased and a change in strategy is needed since students are prone to drug consumption in this difficult and vulnerable time [1] [2]. Nursing students faced to leave classrooms, laboratories and clinical scenarios; cancelling practice in clinical scenarios caused stress, increasing their anxiety and risk behaviors being alcohol and tobacco users.

Educational praxis faces tremendous challenges, among them to improve a better education in a dynamical and complex context; the pedagogic strategies must motivate changes from mentorship where the teacher lectured, to an integral and organized in real-life problems where different disciplines merge to solve a problem, creating the problem-based learning (PBL) approach, which places the student at the center of the process [3]. PBL is a pedagogic strategy employed in health area to strengthen significant learning; it is a didactic system that requires students active involvement in their own learning, i.e., students take the initiative to solve problems [4]. Those involved must have critical thinking and skills to solve challenges, working collaboratively in small teams; as a consequence, the student acquire new knowledge, develop skills for teamwork and solve problems, show leadership, identify needs and improve their communication. PBL introduces real and significant situations, contextualized and spares resources, guidance and instructions to students in order to improve content and skills to solve problems [3]. Nursing students' experiences on drug use and abuse during COVID-19 contingency allowed them to know their adaptive process to the current pandemic, as well as to analyze what they learned due to social isolation and other preventive measures imposed by the government to avoid contagion. To reflect on the complex and radical situation for them being at home, the information gave a wide panorama of their behaviors and attitudes during this period, such that is fundamental create timely prevention strategies to train human resources with real challenges, that develop skills to cope and adapt to avoid drug use and 
abuse in vulnerable populations [4]. The objective of the research was to establish the PBL influence in nursing students' experiences on drugs use and abuse during the COVID-19 contingency.

\section{Methods}

Qualitative, phenomenological research focused in describing the experiences, emotions, feelings, and principles of participants in real and specific settings rescuing their attributes. Phenomenology, more than a totalitarian creed or a philosophical system, is a critical and radical attitude to cope with factual reality that experience grants [5], it promotes liberty and expressiveness of the study subject to describe human experiences in nursing students, as they were lived during the sanitary emergency due to COVID-19, emphasizing the PBL that students acquired regarding drug use and abuse [6] [7] [8].

Twelve female and male nursing students from a public university in Mexico, aged $20-24$ years old from the $5^{\text {th }}$ and $6^{\text {th }}$ semesters participated. Information collection was through semi-structured interview [9]. In four informants a deep interview, at different moments, with 16 zoom sessions lasting $2-3 \mathrm{~h}$ was done. The time frame of the study was September 2020 to January 2021. Signed informed consent was obtained from each participant, and the career authority knew of the project. Qualitative data were read, transcribed and showed to informants for their approval, then they were analyzed according to De Souza Minayo [10] [11].

\subsection{Inclusion Criteria}

They are nursing students, female and male genders, between 20 - 24 years old, from $5^{\text {th }}$ and $6^{\text {th }}$ semesters taking online lectures and without clinical practice at the time.

Participants were enrolled in an optional module of the nursing career, named "Awareness to addictions in health area", then they are small groups since group dynamics are used which are difficult to implement in larger groups.

\subsection{Data Collection}

Data collection was through a semi-structured interview, including 4 questions about tobacco, alcohol use before the pandemic; the use and abuse during the pandemic; the implemented strategies to regulate behaviors; significant learning during the process. Those questions encouraged the interviewer to deploy a mixed strategy, alternating structured and spontaneous questions; the purpose was to keep control on the expressed ideas [9]. In four informants a deep interview was done in different moments, via zoom sessions and students authorized the recording of each session.

\subsection{Ethics and Legal Aspects}

For this research the ethical issues were considered to ensure the validity of the 
work, with diverse sources: Ethical principles of the declaration of Helsinki [12], point number 6 that say "Always must respect the rights of persons to safeguard their integrity. All precautions needed to intimacy respect of persons and to minimize the impact of the research on their physical, mental and personality integrity must be observed". To reach those goals confidentiality, the secrets exposed by the informants must not be revealed, and the recordings must be confidentially used only for this research, and along it limits persons imposed on information must not be exceeded, giving them complete liberty to withdraw.

The Belmont Report [13] clause B, essential ethical principles, considering respect for persons, benefit and justice; as well as clause C, writing de informed consent, a document that contains the required elements such as information, comprehension, and willingness; in addition, to evaluate risks and benefits explaining that no risk exists for this investigation.

\section{Results}

Qualitative data analyses showed that all 12 informants were grouped in four categories and six sub-categories to identify their experiences. In Table 1, it is shown nursing students characteristics, such as gender, age and semester; while Table 2 shows their experiences about drug use and abuse during the sanitary contingency, due to stress and anxiety increase, their skills to identify a problem and to design appropriate solutions for self-care and population care, skills to improve personal interrelationships diminishing the sense of loneliness and isolation, as well as the influence of PBL in their experiences due to COVID-19.

Students' speeches highlighted anxiety and frustration increment due to confinement at home, coexisting with the same persons for long periods and by quitting clinical practices, which in nursing training cut down the experience needed to get abilities in procedures; these situations led them to higher tobacco consumption or in some cases, to smoke marijuana to diminish their maximized emotions.

In the results more female students developed anxiety and frustration that increased tobacco consumption, even marijuana consumption.

Table 1. Characteristics of informants, January 2021.

\begin{tabular}{ccc}
\hline Gender & Age & Semester \\
\hline Female & 20 & $6^{\text {th }}$ \\
Female & 20 & $6^{\text {th }}$ \\
Male & 20 & $6^{\text {th }}$ \\
Male & 20 & $5^{\text {th }}$ \\
Male & 20 & $5^{\text {th }}$ \\
Male & 21 & $5^{\text {th }}$ \\
Male & 21 & $5^{\text {th }}$ \\
Female & 22 & $6^{\text {th }}$ \\
Female & 22 & $6^{\text {th }}$ \\
Female & 22 & $5^{\text {th }}$ \\
Female & 22 & $5^{\text {th }}$ \\
Male & 24 & $6^{\text {th }}$
\end{tabular}


Table 2. Emerged categories.

\begin{tabular}{ll}
\hline \multicolumn{1}{c}{ Category } & \multicolumn{1}{c}{ Sub-category } \\
\hline $\begin{array}{l}\text { Category I Students' experiences about } \\
\text { drug use and abuse during the sanitary } \\
\text { contingency }\end{array}$ & $\begin{array}{l}\text { 1.1) Excessive workloads and higher } \\
\text { responsibility } \\
\text { 1.2) Forced long lasting coexistence with } \\
\text { same persons } \\
\text { 1.3) Maximized emotions }\end{array}$ \\
\hline $\begin{array}{l}\text { Category II Skills development to identify } \\
\text { a problem and design appropriate solutions }\end{array}$ & 2.2) Self-care and family care interventions \\
\hline $\begin{array}{l}\text { Category III Skills development to } \\
\text { improve interpersonal relationships }\end{array}$ & 3.1) Improving family relationships \\
\hline $\begin{array}{l}\text { Category IV PBL influence in nursing } \\
\text { students' experiences on drug use and } \\
\text { abuse due to COVID-19 contingency }\end{array}$ & \\
\hline
\end{tabular}

\section{Discussion}

The sudden and extensive COVID-19 spread triggered a health world crisis where persons felt without control, since social isolation preventive measures to avoid contagion and spread the virus forced people to stay at home; in this situation social and working life halted, schools closed and all students stayed at home, companies stopped everyday production, many other activities diminished such that unemployment increased as well as the fear to visit public sites. These changes produced anxiety and depression in society because a feeling of health and freedom lost. The most recent studies revealed the psychological impact to be confined for a long and undefined time, before this situation nursing students were also involved in the phenomenon since their profession requires essential practical aspects in their training which were interrupted [2] [14]. The majority of the studies reported negative outcomes in peoples' mental health, such as symptoms of post-traumatic stress syndrome, confusion, irritability, fears and risk behaviors [15] [16]. It is known that those disorders are risk factors prone to drug use and abuse; in addition, there was grief due to lives lost, the isolation, decrease in wages and the fear to be sick or die, even exacerbating mental disorders, then family members increased alcohol or other drugs consumption to relieve their anxiety and depression problems [2], which is coincident with Category I Students' experiences about drug use and abuse during the sanitary contingency, and their speeches:

1.1) Excessive workloads and higher responsibility

[ ] During this change I faced more risk factors to alcohol, tobacco and other drugs consumption, excessive stress and anxiety for overload of online home works, since teachers confer all learning responsibility to students, which provoked that students looked for relaxation techniques allowing us to distract of the overload work and felt better. E1

1.2) Forced long-lasting coexistence with same persons 
[ ] In this forced lockdown I consider that had been difficult to be tolerant with my parents because they had a very distinct mentality to my own and that is why I can never express what I feel nor my own opinion, since they call me exaggerated so I was up to my limit and looked for psychological counseling. I started to consume cannabis in low doses to tolerate my family all day long. E8

1.3) Maximized emotions

[ ] My self-esteem and mood had been on the edge because some days I felt fine, but others I felt frustrated for so many changes, there were days with depression and overwhelmed I doubt of my abilities, I smoke very early in the day to calm down. E12

Behaviors related to drug use and abuse are caused by a variety of factors that may increase or decrease the risks. Risk factors are those interpersonal, social or individual present in the surroundings where persons live, and that might increase the chances to create a positive addictive process; these characteristics will predict drug consumption behavior and place the person in a vulnerable situation to start that behavior [17]. Training of professionals in health area must contemplate all these risk factors for drug use and abuse, in the process of teaching-learning for students, to be regarded in self, in the family and in the community, as well as in the most vulnerable population to intervene successfully. Those situations that associate with students' life represent a benefit or proper solution to their needs or problems that most impact their learning, leading to the increase in interest and knowledge acquisition where the student is at the center of the process; the experience contributes to significant learning when students face in real scenarios close to their daily life [18] [19]. Risk factors influence the start and persistency in consumption, accordingly with the substance attributes, user characteristics and trigger context, as it is presented in Category II Skills development to identify a problem and design appropriate solutions, and the speeches that supported it:

2.1) Focus the student on the learning process

[ ] It is important that the basis of the nursing curriculum allow students to have time for self-care, since not everyone had the ability to face stress. Since nursing is one of the lowest in self-care, we shall focus to be conscious as individuals and as a class. E3

[ ] Health mental disorders such as depression and anxiety we faced every day, and unfortunately nobody cares about it. These problems are important risk factors to initiate or keep drug abuse like narcotics, that give the sensation of calm and relief, it is necessary to identify those disorders in ourselves then in the family and community. E4

2.2) Self-care and family care interventions

[ ] During this situation I became more empathic, I found the way to selfmotivate to do recreational activities for better and also I focused on my future plans, I placed my short, medium and long term goals as a motivation to avoid depression, even that confined life is quite heavy. E2 
[ ] With this strategy I understood my role as a health professional in training, we have to self-care first since we know what will happen if we abuse some substances, we have to be congruent with what we say and what we do. E1

[ ] I worked out to reduce my cannabis consumption, and I quit it without consequences. E8

[ ] During this period I talked to my family about alcohol use and abuse, they may think that drinking helped them to felt less stressed or anxious, or to felt fine; however, it is probable that alcohol had the opposite effect. It will not help to feel better and may contribute to triggering new problems, since it is known that alcohol triggers anxiety, depression, fear and panic that may intensify during confinement, as mentioned in the news. E6

There are protective factors to avoid a person initiating drug consumption, to control or diminish its consumption, or to reduce the associated damage; protection factors are cumulative and their interaction is required to have the desired protection, i.e., individuals, their family and their community develop protection factors to avoid substances use or abuse, for example, to have relatives or friends that do not consume tobacco and/or alcohol, or they do but sporadically; this is a support for no consumption or, if they are occasional consumers, not develop substance tolerance [17]. Among all protection factors social abilities development is very important, since that solve immediate problems favoring positiveness, and minimizes immediate and future problems; this is modeled, acquired and developed inside the family, then it is assayed at school and then in society, this same reasoning gave Category III Skills development to improve interpersonal relationships, where interpersonal relationships between the student and its family social environment during the pandemic were observed, and sub-category 3.1 Improving family relationships emerged with the speeches that supported it:

3.1) Improving family relationships

[ ] With the support of my family I increased my mood and realized about myself, to cheer me up and to propose a change in my lifestyle and emotional control. This pandemic tied me up to my family since student life is time demanding, and most of the day I was at school and now with online lectures, I can eat and talk at home. Even it is great to share with them parts of my lectures, not at all understood, but they help me and support me. E12

[ ] I have always been so close to my family and communicate with them constantly, family relationships were strengthened, since my mother is a nurse and because we knew she was to be in contact with COVID-19 patients all family members supported her emotionally, we always were together then she had confidence on us, and even there is a risk we always think positively, no matter what happens. E7

[ ] Inside my family I noticed how complex was to adapt, to be together and be respectful to each other, for all of us was a difficult process but as time went by we got a better family relationship, I got along with my sisters and tied bonds with my mom. E2 
Abilities and competencies on attitudes and values development are needed to conscious and informed performance in students in different settings to scholar ones [20]. By implementing the pedagogic strategy of PBL, students were able to identify risk and protection factors facing the pandemic from their experiences, as well as give strategies to compare them in time. The structure and the process to solve a problem is dynamic in students, which motivated and enriched conscious learning and collaborative and systematic work, as a learning experience [1] [20]. Working with PBL activity involved the discussion of a problem as real as possible, that triggers interest among participants and learning emerges from the teamwork experience; it is a technique that stimulates self-learning and lead students to practice by facing real situations and identifying knowledge deficiencies [1] [2]. This support Category IV PBL influence in nursing students' experiences on drug use and abuse due to COVID-19 contingency, as observed in the speeches that related the technique with the experiences and the learning acquired during the pandemic:

[ ] To live this real problem, to share it and worked with teammates had been a great opportunity to get better, learn and grow as a person, as a student and as a worker. It helped me to plan short-term goals, to be close and enjoy my family, value their love and warmth; it helped me to diminish alcohol consumption and tobacco smoking. Still I have to work on my emotional status, but so far I am glad and calm seeing my progress working with PBL. It helped me to mature, control my impulses and regulate my consumption. E1

[ ] Facing this problem I learned my courage as a person, no more comparing myself with others even I liked to compete with peers at elementary, junior high and high school, it worked ok for me; however, this dynamic made me realize that other persons have different learning abilities and habits that I do not, so that frustrated myself at the beginning. During the pandemic I understood that each person has a different way to learn and solve current problems, and by sharing that we all get better ways to solve them. $\mathrm{E} 2$

When we face new situations, solve problems or create new ideas, the emotional response in each situation triggers our mental resources. The first interpretation of a new situation always hits emotions, feelings and attitudes, influencing the sharpness to identify emotions, and control them via emotional intelligence [21]. During confinement nursing students' experienced a radical change in their lifestyle, leading to a change in their emotional status affecting how the student performs in social relationships, and even in scholar performance. This triggered resilience, emotional intelligence and a constant adaptive process, through reflection and analysis of the facing situation. The objectives of this research were fulfilled, described experiences with students showed a wide panoramic of behaviors and emotions along the contingency period. That was very important because the PBL was analyzed and worked out, emphasizing their resilience to current life situations.

Zoom sessions supported students to share their concerns, emotions and 
thoughts, channeling anxiety in an opportune way.

\section{Conclusion}

Results shown that the adaptive process to the pandemic by nursing students was complex and difficult at the beginning, the radical changes included every aspect of their personal, familial and social lives, where they perceived themselves as vulnerable and highlights that through PBL strategy they acquired and developed knowledge, abilities and attitudes about how to face drug use and abuse; they reached significant learning that enabled them facing their problems appropriately and at their own pace, as well as help the family regarding each participant set. PBL is a teaching-learning strategy that enforces knowledge acquisitions and abilities and attitudes development. The main goal is not only that, but the integral professional training; the nursing student identified objectives, it was committed, discovered, and wished to learn more leading to feedback and stimulated its leadership of communication and decisions making, creativity, critical thinking and teamwork.

\section{Acknowledgements}

Authors thank PAPIME 300920, DGAPA, U.N.A.M. for financial support.

\section{Authors Contributions}

All authors collaborated in the research. DCTP designed the protocol and wrote the manuscript. DCTP and RVM revised and edited the manuscript for publication. AILG, ODVR, VPCP, collected and analyzed data. All authors read and approved the final manuscript.

\section{Conflicts of Interest}

Authors declare no conflict of interest.

\section{References}

[1] Guevara, G. (2010) Problem-Based Learning Like Didactic Technique for the Education of the Subject of the Recursion. InterSedes, 11, 142-167. (In Spanish) https://www.redalyc.org/pdf/666/66619992009.pdf

[2] Castillo-Megchun, I.C., López-Rossell, C.G., Padilla-Rivera, M.A., Villalobos-Molina, R. and Tapia-Pancardo, D.C. (2021) Problems-Based Learning during COVID-19 Pandemic: Experiences by Nursing Students. Open Journal of Nursing, 11, 920-932. https://doi.org/10.4236/ojn.2021.1111075 https://www.scirp.org/journal/ojn

[3] Cevallos-Torre, L. and Botto-Tobar, M. (2019) Problem-Based Learning: A Didactic Strategy in the Teaching of System Simulation. Springer, Berlin. https://link.springer.com/content/pdf/10.1007\%2F978-3-030-13393-1.pdf

[4] Laguna, M.K.D., Matuz, M.D., Pardo, V.J.P. and Fortoul, V.D.G.T.I. (2020) Problem-Based Learning as a Didactic Strategy for Medical Education. Revista Facultad de Medicina, 63, 42-47. (In Spanish) https://doi.org/10.22201/fm.24484865e.2020.63.1.07 
[5] Busetto, L., Wick, W. and Gumbinger, C. (2020) How to Use and Assess Qualitative Research Methods. Neurological Research and Practice, 2, Article No. 14. https://doi.org/10.1186/s42466-020-00059-Z

[6] Patton, M.Q. (2002) Qualitative Research \& Evaluation Methods. In: Integrating Theory and Practice, Sage Pub. Inc., Thousand Oaks, 832.

[7] Ruiz, J.I. (2012) Qualitative Research Methodology. Universidad de Deusto, Bilbao.

[8] Rodríguez-Hidalgo, A.J., Pantaleón, Y., Dios, I. and Falla, D. (2020) Fear of COVID-19, Stress, and Anxiety in university Undergraduate Students: A Predictive Model for Depression. Frontiers in Psychology, 11, Article ID: 591797. https://doi.org/10.3389/fpsyg.2020.591797

[9] Galvin, J., Souminen, E., Morgan, C., O’Connell, E.J. and Smith, A.P. (2015) Mental Health Nursing Students' Experiences of Stress during Training: A Thematic Analysis of Qualitative Interviews. Journal of Psychiatric and Mental Health Nursing, 22, 773-783. https://doi.org/10.1111/jpm.12273

[10] De Souza Minayo, M.C. (2010) The Structuring Concepts of Qualitative Research. Salud Colectiva, 6, 251-261. (In Spanish)

[11] Berenguera, A., Fernández de Sanmamed, M.J., Pons, M., Pujol, E., Rodríguez, D. and Saura, S. (2014) Listen, Observe and Comprehend. Recovering the Narrative in Health Sciences. Contributions from Qualitative Research. Institut Universitari d’Investigació en Atenció Primària Jordi Gol (IDIAP J. Gol), Barcelona. (In Spanish)

[12] Resnik, D.B. (2020) What Is Ethicsin Research \& Why Is It Important? https://www.niehs.nih.gov/research/resources/bioethics/whatis/index.cfm

[13] (1979) The Belmont Report. Ethical Principles and Guidelines for the Protection of Human Subjects of Research.

https://www.hhs.gov/ohrp/regulations-and-policy/belmont-report/read-the-belmon t-report/index.html

[14] Al-Adawi1, M., Al-Habsi1, S., Al-Hashmi1, N., Al-Bulushi1, S. and Al-Alawi., K. (2021). Mixed Expectations in the Recruitment Settlement during COVID-19 Pandemic: Experiences of Newly Employed Nurses in Oman. Open Journal of Nursing, 11, 542-556. https://doi.org/10.4236/ojn.2021.116046 https://www.scirp.org/journal/ojn

[15] Brooks, S.K., Webster, R.K., Smith, L.E., Woodland, L., Wessely, S., Greenberg, N., et al. (2020) The Psychological Impact of Quarantine and How to Reduce It: Rapid Review of the Evidence. The Lancet, 395, 912-920. https://doi.org/10.1016/S0140-6736(20)30460-8

[16] Adriano da Silva, J., Catissi, G., Bernardes de Oliveira, L., Reis Dal Fabbro, D., Jaures, M., Plack, E., Borges, G.C., Racy, F., Ferreira Nunes, A., Miranda, R.M., Noguchi Maki, D.T., Pinto Schettino, G.P., Laselva, C.R. and Ribeiro Leão, E. (2021) COVID-19: Feelings Experienced by Nurses, Physiotherapists, and Medical Doctors in a Brazilian Field Hospital. Open Journal of Nursing, 11, 390-406.

https://doi.org/10.4236/ojn.2021.115034

https://www.scirp.org/journal/ojn

[17] Tapia, D., Villalobos, R., Cadena, J., Ramírez, J. and Ostiguín, R. (2018) Education, Technology and Health for Adolescents: Models of Thinking, Learning, Rmotions and Prevention of Use and Abuse of Addictive Substances. RU-Iztacala Autonomous National University of Mexico, Mexico City. (In Spanish)

[18] Tapia-Pancardo, D., Gutiérrez-Martínez, J.C., Martínez-Mondragón, R., Rivera-Ramírez, C.G., Piñón-Atilano, C., Hernández-Bravo, W.J., Navarrete-Mejorada, 
A., Sánchez-Gómez, V. and Villalobos-Molina, R. (2020) Immersion Tools as a Strategy for Adolescents Mental Health: A Qualitative Study. Health, 12, 866-875. https://doi.org/10.4236/health.2020.127064

[19] Acevedo-Peña, M., Ostiguín-Meléndez, R.M., Cadena-Anguiano, J.L., Ibarra-Gonzalez, M.P., Hernández-Hernández, J.R., Villalobos-Molina, R. and Tapia-Pancardo, D.C. (2021) Problem-Based Learning in Situ Applied to Students in the Assessment of Nursing Process. Open Journal of Nursing, 11, 378-389.

https://doi.org/10.4236/ojn.2021.115033

https://www.scirp.org/journal/ojn

[20] Tapia, D., Villalobos, R., Ostiguín, R., Ibarra, M. and Cadena, J. (2021) Active Learning of Socioemotional Abilities and Adolescents to Prevent Risk Behaviors. Faculty of Higher Studies Iztacala, RU-Iztacala, Autonomous National University of Mexico, Mexico City. (In Spanish)

[21] Goleman, D. (2011) The Brain and Emotional Intelligence: New Insights. More than Sound, Florence. 